\title{
Reflecting on the Interaction of Self-Control and Morality in Situational Action Theory: Comparing Absolute and Relative Effects of Self-control in 28 Countries
}

\section{Ilka Kammigan ${ }^{1}$ (D)}

Accepted: 29 November 2021

(c) The Author(s) 2022

Keywords Situational action theory (SAT) - Interaction of self-control and morality · Falsifiability $\cdot$ Semi-elasticities $\cdot$ ISRD

\section{Introduction}

Situational Action Theory (SAT) proposes that crime is the outcome of a process of decision-making, in which self-control is a relevant factor only under certain conditions. One condition is the extent to which actors disregard crime as a morally unacceptable action alternative. There is however some disagreement in the literature on whether such personal moral values enhance or dampen the crime-reducing effect of self-control.

To date, most research has found stronger effects of self-control for actors with lower levels of morality (e.g., Li 2004; Pauwels 2015; Ivert et al. 2018). A number of these studies that have tested the interaction in the context of SAT see their results in accordance with the theory's principle of the conditional relevance of controls (e.g., Svensson et al. 2010; Wikström and Svensson 2010), which postulates that self-control only becomes relevant if the moral filter has failed. This is indicated - so these researchers argue - by lower levels of morality.

However, SAT more straightforwardly implies the opposite prediction of stronger effects of self-control when morality is strong: "The ability to exercise self-control may be a relevant factor for individuals' law abidance only when they are motivated to and consider committing acts of crime contrary to their morality." (Wikström and Treiber 2007, 250) The idea that self-control requires strong personal moral standards has received less attention in

1 Faculty of Humanities and Social Sciences, Department of Empirical Social Research Methods and Statistics, Helmut Schmidt University Hamburg, Holstenhofweg 85, 22043 Hamburg, Germany 
the literature on SAT (e.g., Kammigan 2017, 267; Hirtenlehner and Reinecke 2018, 4) and only very limited empirical support.

For Hirtenlehner and Kunz (2016, p. 397), "[k] ey to reconciling the seeming contradiction is the temporal ordering of the two-stage perception-choice process." However, this does not solve but rather describes the logical inconsistency: First, a failed moral filter (weak moral standards) provides something to control, and in reaction to that self-control enforces strong moral standards. Both conditions cannot be satisfied by the same actor's individual morality, which usually should not change within the same process of decision-making.

Therefore, does the fact that strong morality is expected to do both, enhance and dampen the effects of self-control, render SAT unfalsifiable? Extending the words of Hirtenlehner and Reinecke (2018, p. 5) on this topic, there appears to be more than just "[...] a whiff of ambiguity [that] remains. Resolving this dissonance in future works is highly advisable." Taking up on their request, this paper is attempting to contribute a piece to the puzzle by identifying one theoretical and two methodological sources for the ambiguity and by proposing possible ways to overcome these problems.

In the next section, the paper starts with SAT's basic assumptions, focusing on the circumstances under which self-control reduces crime in the theory's current formulation. Although most research seems to contradict those predictions, there are however some plausible reasons why the results actually do not necessarily falsify SAT. The subsequent section discusses those reasons and their implications for the general falsifiability of the theory: As a first reason, it identifies a logical inconsistency between older SAT publications and the theory's current formulation, but argues for keeping only the recent prediction of enhancing interactions. But even then, morality's correlation with other constructs of the theory, that indeed give rise to a self-control relevant moral-filter failure, opens up the possibility to also interpret dampening interactions in line with the current formulation of SAT. Finally, under certain circumstances, it is even possible to generate the desired results, depending on how the conditional effects of self-control are being modeled. However, rather than rendering the theory empirically untestable, the two methodological issues caution researchers to model their analyses carefully.

In response to the suggestions being made, the paper proceeds with an empirical test of SAT's prediction of enhancing interactions, derived from the idea that self-control requires intact moral standards. The paper will also investigate whether the common finding of dampening interactions is indeed due to morality's correlation with other constructs that are involved in a self-control relevant moral-filter failure. Finally, the last section discusses the results and their implications for testing SAT.

\section{The Three Conditions for Self-control in SAT's Current Formulation}

According to SAT, criminal acts are outcomes of people perceiving crime as morally acceptable action alternative and then choosing it over non-criminal alternatives (perceptionchoice process). While moral rules (of the person and the setting) affect the perception of criminal action alternatives (moral filter), controls (self-control and setting deterrence) affect the actor's subsequent choice. Actors do not even perceive crime as action alternative if neither the person nor the setting moral rules allow crime. In such situations, all criminal action alternatives are filtered out and controls are irrelevant. Controls only become relevant 
if the actor perceives crime as option, which is the case if either the person or the setting moral rules allow crime.

However, if both allow crime, controls do neither come into play, because there is no situationally relevant norm against crime that can be enforced. Just as setting deterrence is a “[...] process by which the (perceived) enforcement of a setting's moral norms (by creating concern or fear of consequences) succeeds in making a person adhere to the moral norms of the setting" (Wikström et al. 2012, 26), self-control is "an individual's success at acting in accordance with his/her morality [...]" (Wikström and Treiber 2007, 243).

The perception-choice process can either take place in a deliberate form, in which actors more or less consciously ponder over their action alternatives, or it can take place in a habitual form, in which actors perceive only one effective action alternative (in familiar, emotional, or stressful situations) and thus choose it automatically. Because there is no real choice, controls are irrelevant in habitual action (for more details see e.g., Wikström, 2010, 221-234; Wikström et al. 2012, 11-29).

Summing up, there are three conditions for controls to become relevant, which will be described in more detail below: (1) A failure of the moral filter, i.e., weak moral rules that encourage crime (there must be something to be controlled), (2) a controller holding strong moral standards against crime that can be enforced (there must be someone with a moral reason to exercise control), and (3) a deliberate process of decision-making.

\section{Failed Moral Filter}

As has been outlined in the introduction, most studies on the interaction between self-control and morality find stronger effects of self-control for those with lower levels of morality (Higgins and Makin 2004; Li 2004; Schoepfer and Piquero 2006; Svensson et al. 2010; Wikström and Svensson 2010; Pauwels 2012, 2015; Bruinsma et al. 2015; Hirtenlehner 2015; Hirtenlehner and Kunz 2016; Ivert et al. 2018; Kroneberg and Schulz 2018). In order to make a case for their results, a number of studies that are based on SAT refer to condition (1) of a failed moral filter (e.g., Svensson et al. 2010; Wikström and Svensson 2010; Hirtenlehner and Kunz 2016; Ivert et al. 2018). Drawing on SAT's principle of the conditional relevance of controls, which includes the notion that controls in general only become relevant if the actor perceives crime as an acceptable action alternative (e.g., Wikström et al. 2012, 25), they conclude that self-control should have stronger effects for those, whose lower levels of morality let them perceive crime as alternative (e.g., Wikström and Svensson 2010).

Upon closer inspection however, the principle of the conditional relevance of controls does not posit that any form of control comes into effect for any constellation of moral-filter failure. Rather, external control (setting deterrence) becomes relevant if only the internal part of the moral filter (individual morality) has failed, while internal control (self-control) becomes relevant if only the external part of the moral filter (setting moral rules) has failed (see Fig. 1's black part and Fig. 2(2)). Thus, deterrence should have stronger effects for actors with low levels of morality, while self-control should have stronger effects for those acting in settings with weak moral rules (e.g., Wikström et al. 2012, 26-27; Wikström 2010, 233-234). The idea, that self-control is conditional on low individual morality letting people see crime as action alternative, appears to be exactly what the theory does not predicthigher levels of morality are not expected to dampen the effects of self-control. 
Fig. 1 SAT's principles of "moral correspondence" and of the "conditional relevance of controls" (figure adapted from Wikström, 2010, 233, Fig. 12.4., see also Kammigan 2017, 51, Fig. 5)

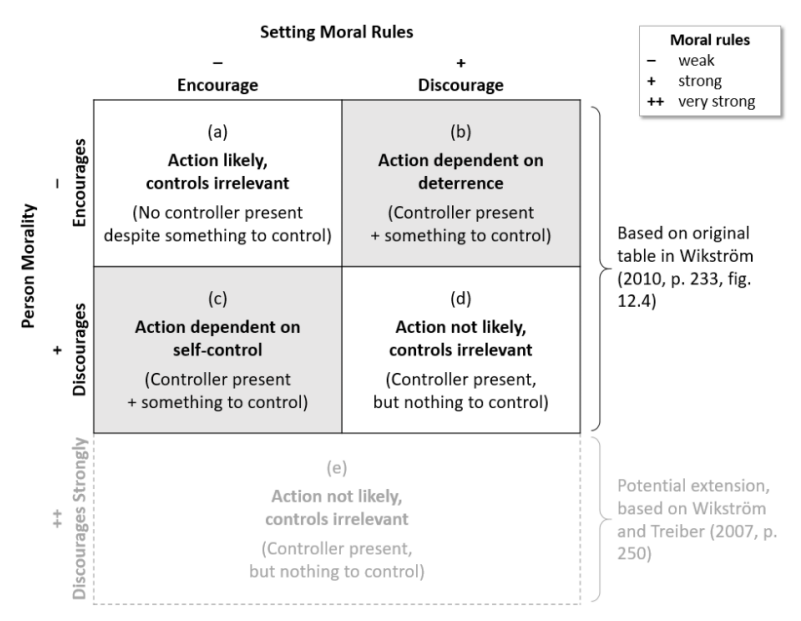

\section{Moral Reason to Exercise Control}

Rather, SAT implies that higher levels of morality enhance the effect of self-control, because they provide the moral basis to be enforced (see Fig. 1's black part, Fig. 2(1), and Fig. 3(1)). To date, this idea finds very slight empirical support only in a part of the analyses by Antonaccio and Tittle (2008), Bruinsma et al. (2015), and possibly Eifler (2015), and is rooted theoretically in SAT's conceptualization of self-control.

The theory differentiates between the capability to control as a trait of the person or of the setting, and the process of actually exercising control (cf. Wikström, 2010, 232). The capability for self-control is based on an individual's cognitive abilities (Wikström and Treiber 2007, 251), which can situationally vary around a general level, for example because of intoxication or depletion of cognitive resources (Wikström and Treiber 2007, 255-256). This ability is one of the ingredients required for a successful process of controlling the self in a specific situation. The other ingredient is a moral basis to enforce, without which the mere ability to control would be useless. This is reflected in SAT's definition of the process of self-control as "the successful inhibition of perceived action alternatives, or interruption of a course of action, that conflict with an individual's morality" (Wikström and Treiber $2007,244)$. The capability for self-control can thus only contribute to the choice of noncriminal action alternatives (and its crime-reducing potential can only manifest in having successfully controlled the self), if it is guided by strong individual morality (Fig. 1's black part) (see Kammigan 2017, 267; Hirtenlehner 2015, 261; Hirtenlehner and Kunz 2016, 396397; Hirtenlehner and Reinecke 2018, 4). Technically, it is self-control ability that interacts with strong morality within the process of controlling the self, the outcome of which in turn relies on the ingredients and their interaction.

Moral rules therefore do not only operate as a moral filter in the perception process: "Together with controls (the ability to exercise self-control and deterrence) moral rules also influence how a person (when he or she deliberates) assesses the alternatives for action that come to mind." (Wikström, 2010, 222). In their latter function within the process of choice, which allows for free will and rational choice (cf. Wikström 2006, 77-78), moral rules may be understood as a cost factor of crime. 
The role of moral rules in a deliberate process of choice and the conceptualization of selfcontrol in SAT is similar to that of Tittle et al. (2004), who distinguish between the capacity and the desire to exercise self-control, although for them it is not only the actor's morality but also social and other costs of the behavior that might affect the actor's desire to exercise self-control. Just being able to control does not keep people from committing crime if they do not want to control themselves: "[...] those who can control themselves may not always want to do so; instead, they may sometimes deliberately choose to commit criminal acts [...]." (Tittle et al. 2004, 147) Tittle et al.'s (2004) own results do however not support their prediction of stronger self-control ability effects for those with a strong desire in exercising self-control. The notion of moral standards as an interest in exercising self-control is also prominent in Baumeister and Exline's (1999) conceptualization of "self-control as the moral muscle", proposing that the capability to exercise self-control ("willpower") is irrelevant if people lack moral standards: "[...] people who do not endorse moral standards may behave in immoral ways regardless of their degree of willpower." (Baumeister and Exline 1999, 1189).

\section{Moral Conflict: Combining Both Conditions}

However, effects of self-control for the high-morality group also rely on the possibility that there is something to be controlled for this group at all (i.e., that a moral-filter failure is possible): Both conditions explicated so far must be met simultaneously for self-control to be successful.

Person and setting moral rules are designed as counterparts in satisfying the two conditions. This is reflected in SAT's more complete version of the principle of the conditional relevance of controls that also entails the principle of moral correspondence (Fig. 1's black part): Controls are irrelevant in situations of moral correspondence-which in turn make criminal acts likely or unlikely per se, depending on whether the corresponding rules encourage or discourage crime-and are only relevant in situations, in which actors perceive a moral conflict between their own and the setting's moral rules (e.g., Wikström, 2010, 233-234). Accordingly, "[c]ontrol is conceptualized in SAT as the process by which a person manages conflicting rule-guidance (Wikström et al. 2012, 25-26). More graphically, controls have an effect in the antidiagonals $(b, c)$ but not in the main diagonals $(a, d)$ of Figs. 1 and 2(3).

The special case of self-control is defined as the "[...] process by which a person succeeds in adhering to a personal moral rule when it conflicts with the moral norms of the setting" (Wikström et al. 2012, 26). Thus, self-control only comes into action if the setting part of the moral filter has failed (weak setting rules) and the actor has a personal moral reason to exercise self-control (strong individual morality) (cell (c), Fig. 1). This implies that even the high-morality group can be encouraged by deviant settings to consider breaking a rule they themselves hold. In chronological order, the process of controlling the self (choice process) is initiated by a failure of the setting moral filter (perception process), and in that sense interacts with weak setting rules. However, "the process of self-control is largely unobservable" (Kroneberg and Schulz 2018, 57). But the initiation of this process activates its observable ingredients, i.e., self-control capability and its interaction with strong morality, which are thus also interacting with weak setting rules (twoway-interaction of self-control ability and setting rules, threeway-interaction of ability, morality, and setting rules). 
Schepers and Reinecke (2018), Pauwels (2018), and Hirtenlehner and Leitgöb (2021) have tested the effects of self-control ability across four groups that mirror the four categories describing SAT's relevant combinations of person and setting moral rules (cells a-d, Fig. 1). However, they find strongest effects when both, individual and setting moral rules encourage crime. Eifler (2015) has tested the interaction between self-control ability and morality in subsamples that represent settings of different criminogeneity. While the interaction was significant only for the most criminogenic setting (as expected), its direction remains unclear: Eifler interprets it as self-control enhancing the effects of morality (as predicted by SAT), but the signs of her regression coefficients suggest otherwise.

\section{Small Note on Deliberation}

As a third condition, "SAT proposes that controls only come into play in the explanation of acts of crime when people [...] deliberate [...]". (Wikström et al. 2012, 25) While situations of moral conflict always indicate deliberate action, the theory does not make clear whether situations of moral correspondence always indicate habitual action (as interpreted by Kroneberg et al. 2010; Kroneberg and Schulz 2018; possibly in accordance: Wikström and Treiber 2007, 258; Wikström, 2010, 227; possibly suggesting otherwise: e.g., Wikström and Treiber 2007, 247; 248, Figs. 1 and 2; Wikström et al. 2012, 25). If that was the case, moral correspondence vs. conflict and habitual vs. deliberate action would overlap completely. ${ }^{1}$

\section{Why Most Research Does Not Necessarily Falsify SAT}

It appears that in its current formulation, SAT quite clearly predicts stronger effects of selfcontrol for higher levels of morality (and weak setting rules) - how, then, can researchers plausibly argue that the frequent empirical finding of stronger self-control effects for lower levels of morality is nonetheless in accordance with the theory's condition of a moral-filter failure?

\section{Theoretical Ambiguity}

First, researchers could refer to some passages in older publications on SAT, which imply that self-control has no effect when morality is very strong, thereby excluding highest levels of morality from the theory's current rule that strong moral standards increase the effect of self-control.

Back in 2004, Wikström declared "[...] that the main relevance of self-control for individual's crime is for those whose morals (values, commitment, emotions) 'permit' them to see a particular act of crime as an alternative.” (p. 17) Similarly, Wiktröm and Treiber stated in 2007 that "[i]f an individual's morality does not 'permit' him/her to see crime as an alternative, self-control will not enter into the process of choice (and an individual's ability to exercise self-control will be irrelevant to his/her choice of action)" (p. 250). This lends some theoretical support to the idea that self-control might have stronger effects once somewhat weaker than very strong levels of morality let people perceive crime as option. If, however,

${ }_{1}^{1}$ And crime could not be filtered out deliberately from the realm of morally acceptable options (cell (d), Fig. 1). 
morality is so weak that it becomes deviant, self-control is not expected to have effects anymore, despite the moral filter having failed (cf. Wikström 2004, 17). "In this case, only deterrence (fear of consequences) may act as a potential inhibitor preventing the individual from acting upon his/her motivation" (Wikström and Treiber 2007, 248).

Technically, this view implies three crucial levels of morality, which condition the effects of self-control in a nonlinear fashion (see Figs. 1 and 2(4), and Fig. 3(3)): As morality increases from low to medium, effects of self-control should increase, because actors begin to develop a moral reason to control themselves. This matches the prediction in SAT's current formulation. But as morality further increases from medium to very strong, effects of self-control should, in contrast to the current formulation, decrease again, because actors begin to filter out all criminal action alternatives as morally unacceptable.

The dampening interactions found in most studies are thus in accordance with the latter part of the nonlinear hypothesis specifically derived from the older SAT literature. The lack of empirical support for the first enhancing part of the nonlinear hypothesis could be explained with Hirtenlehner and Reinecke's (2018, p. 5) idea that the group of low morality might be too rare to noticeably affect results. If this group is basically not represented in researchers' samples, their studies do not allow to draw any conclusions about the effects of self-control when morality changes from low to medium.

However, the theoretical ambiguity about the effects of self-control when morality is very strong would indeed render the theory unfalsifiable. Moreover, the above quoted older passages also challenge other fundamental propositions of SAT as laid out in later publications from about 2010 on (e.g., Wikström, 2010; Wikström et al. 2012) and as described in the previous sections. The older assumption implies that strongly internalized conventional norms alone are sufficient to filter out criminal action alternatives, so in the case of very strong morality the moral filter would operate independently of setting rules. Yet, from the whole conceptualization of the current SAT formulation as depicted in the black part of Fig. 1 follows that even a group of very strong morality can be susceptible to being encouraged by deviant settings: What makes people filter out criminal action alternatives and thus renders (self-)control irrelevant are situations, in which actors with strongly internalized conventional norms act in settings with corresponding moral rules (also emphasized by Kroneberg and Schulz 2018, 62). Thus, the older quotes deny how an intact moral filter is currently constructed in SAT, and partly override the theory's principle of moral correspondence and moral conflict between personal and setting moral rules as conditions for the (ir) relevance of controls.

But keeping in mind that SAT is an evolving theory that has been refined over the years, it might be reasonable to treat the contradicting passages in the older publications as outdated, or to reinterpret them as actually referring to the situation of moral correspondence depicted by Fig. 1's cell (d). Based on this view, this paper considers the ambiguity as dissolved and SAT as not inherently unfalsifiable. Row (e) (Figs. 1 and 2(4)) is discarded as currently unfounded (which is why it is kept in grey), and SAT's prediction remains quite clear: The effects of self-control should increase with higher levels of morality (Figs. 2(1), and 3(1)), which however seems to be contradicted by most research results. 
Fig. 2 Expected interactions between self-control and its moral conditions in SAT
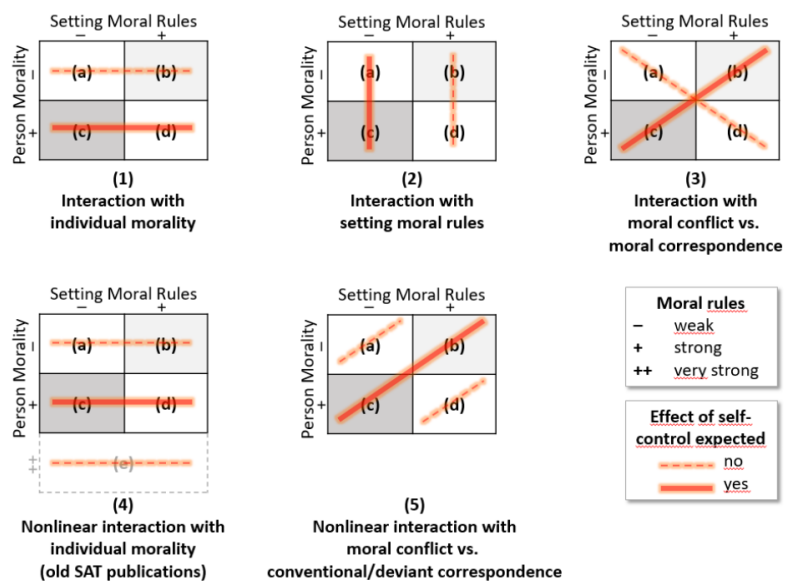
moral correspondence

\section{Confounding and Mediation}

But even without the theoretical foundation in the older passages, the common finding of increasing self-control effects for lower levels of individual morality can be interpreted in accordance with SAT.

In light of SAT's current assumption that self-control becomes relevant if the external part of the moral filter (setting moral rules) has failed, one could consider whether individual morality also captures the moral rules of those settings the respondent is frequently exposed to. Socialization and self-selective processes, it could be reasoned, lead to a tendency of individuals to encounter settings with moral rules that correspond to their own morality (cf. e.g., Wikström and Treiber 2009, 92-93; Akers 2009, 55-56; Seddig 2014; Kroneberg and Schulz 2018, 62). Then setting moral rules would confound (socialization) and mediate (self-selection) morality's relationship with the effects of self-control. What thus causes an unwanted bias for tests of SAT's strong moral standards to enforce condition, opens up several possibilities of interpreting the common research findings in accordance with the current formulation of SAT, where such bias is essential to justify the use of morality as a proxy.

\section{Morality Measures Setting Rules}

First, the morality variable may be interpreted as a proxy for setting moral rules. Then the studies having tested the interaction between self-control and morality would have indirectly tested the interaction between self-control and setting moral rules and thus SAT's condition of a failed setting moral filter (Fig. 3(2)), for which the theory would indeed predict stronger effects of self-control with weakened setting moral rules (Fig. 2(2)).

\section{Morality Measures Moral Correspondence}

Second, Kroneberg and Schulz (2018, p. 62) submit that, although it is not strong individual morality per se (as was implied by the older version) but a situation of moral correspondence that gives rise to an intact moral filter, an intact moral filter may still be measured 
(1)

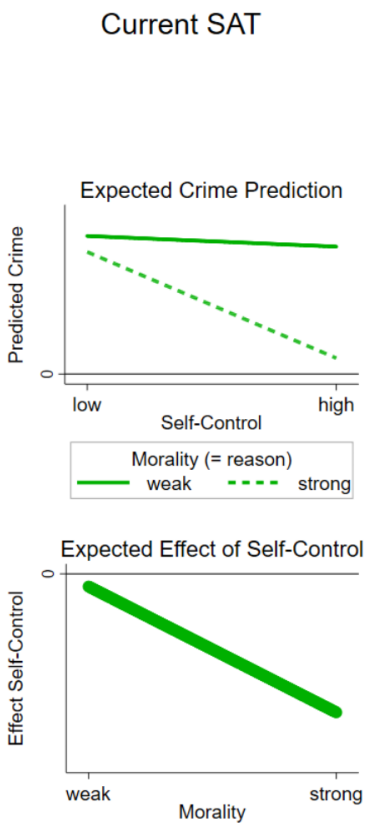

(2)

Current SAT:

Morality Measures

Setting Rules
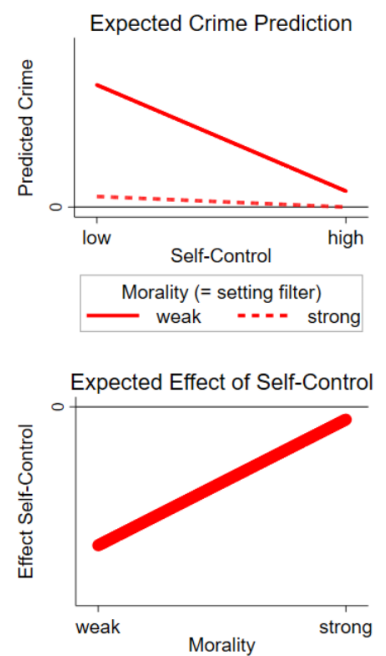

(3)

Current SAT:

Morality Poles Measure

Moral Correspondence

$+$

Old SAT
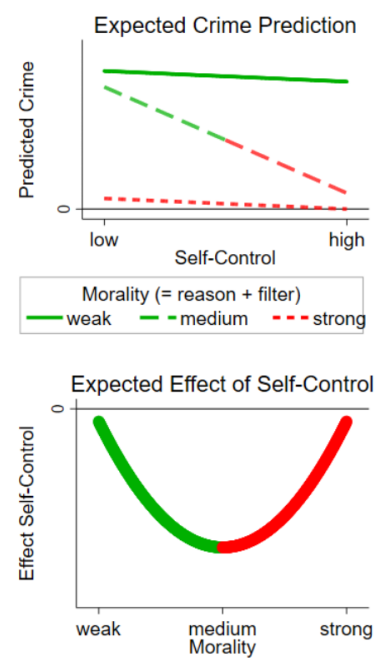

Fig. 3 Expected effects of self-control when the role of (a measure of) morality is interpreted differently: (1) Morality enhances effects of self-control, (2) morality dampens effects of self-control, (3) morality enhances and dampens effects of self-control (nonlinear relationship)

by strong individual morality. If individuals with strongly internalized norms tend to face settings with similar moral rules, the two poles of individual morality (strong conventional and deviant morality) may actually measure the likelihood of situations of moral correspondence, with the correspondence specifically of conventional norms defining an intact moral filter. Extreme levels of morality would render controls irrelevant, not only because all conventional or all deviant options are filtered out, but according to Kroneberg and Schulz (2018, p. 62) also because such situations of moral correspondence evoke habitual action. The authors conclude that "[b]asically all studies that have tested the role of self-control in SAT have disregarded the rules of the setting and implicitly subscribed to this assumption." (2018, p. 62).

Their interpretation implies that all three conditions for controls can be measured simultaneously by individual morality. All of them would be satisfied at medium levels, indicating the presence of deliberate action and a moral conflict between a somewhat weakened moral filter and a still strong enough moral reason to exercise control, but not at the two poles, where a lack of deliberate action is accompanied by a lack of either a moral filter failure (strong conventional morality) or of moral standards to be enforced (strong deviant morality). Technically, Kroneberg and Schulz operationalize the three diagonals in Fig. 2(5) by three crucial levels of individual morality. Similar to the assumptions in older SAT pub- 
lications (Fig. 2(4)), they expect the effects of (self)control to be nonlinearly related to the morality variable, with an effect for medium levels, but not for its two poles (Fig. 3(3)).

In line with this, Hirtenlehner and Reinecke (2018, p. 5) recommend to "switch to the examination of nonlinear moderation relationships" as a "a promising avenue for future research dedicated to the interplay of morality and self-control". Yet, even the studies that have tested the effects of self-control ability across three or more levels of morality (Antonaccio and Tittle 2008; Bruinsma et al. 2015; Kroneberg and Schulz 2018) were not able to unveil the expected enhanced effects of self-control when morality increases from low to medium. As has been outlined above, Hirtenlehner and Reinecke (2018, p. 5) suppose that "[i]t may well be that [...] authors observe larger crime-inhibiting effects of the ability to exercise self-control among respondents of lower morality because the sampling frames underlying their studies do not include individuals holding strong antisocial moral beliefs".

\section{Adjusting for Setting Rules}

But although both, enhancing and dampening interactions can be interpreted in accordance with the current formulation of SAT (on the grounds of Kroneberg and Schulz' (2018) interpretation at least for certain ranges of morality), this does not render SAT empirically unfalsifiable. The dominant finding of dampening interactions is only in accordance with the theory if it is indeed due to morality's correlation with setting rules, which is something that is testable: One way to eliminate such alternative explanations is to statistically control for setting rules.

Yet, controlling away the effect of setting rules might not be sufficient to detect the enhancing interactions derived from SAT's moral standards to enforce condition. (In Kroneberg and Schulz' interpretation, adjustment is not even necessary to detect the enhancing part of the nonlinear relationship between low and medium levels of morality-but would not harm either. Rather, statistical procedures accounting for nonlinearity and a sample including the deviant morality group are necessary to test their interpretation, but might neither suffice to detect the enhancing part of their assumed nonlinear relationship.) This paper submits that tests of the moral standards to enforce and moral-filter failure conditions call for different statistical treatments, regardless of whether they are tested separately or as parts of one nonlinear hypothesis. Probably, most research was simply not designed to detect enhancing interactions, because it has not taken into account the nature of the conditional effect of self-control as discussed in the next section.

\section{Modeling the Conditional Effects of Self-Control}

Thus, even if most research has not found enhancing interactions, this does not necessarily falsify the assumption that the execution of self-control relies on strong moral standards. The reason rests upon the notion that the conditional effects of self-control can be measured in either absolute or relative terms.

Absolute (marginal) effects denote the change in crime units for a one-unit change in self-control. Relative effects can be measured as semi-elasticities, which quantify the proportional change in crime for a one-unit change in self-control. Marginal effects can be transformed into semielasticities, but semielasticities can be also obtained directly by log- 
ging the dependent variable in linear regression (Wooldridge 2013, 39-42), or by applying regression models that predict the natural $\log$ of the dependent variable, e.g., negative binomial regression (Hilbe 2011, 129-130).

The choice of one or the other type can lead to interactions of opposite directions: In a group where there is little to be controlled, i.e., in which the baseline crime rate is low, even a small reduction of crime may be much in relation to the low reference point. In a group where there is more to be controlled, i.e., in which the baseline crime rate is higher, more crime must be reduced to achieve the same proportional change. Thus, despite larger absolute reductions of crime in groups with much baseline crime, the proportional change may still be larger in groups with less baseline crime. The common finding of larger marginal effects of self-control for lower levels of morality does therefore not exclude the possibility that proportional changes are larger for higher levels of morality.

But does this render SAT (and also other theories that specify similar interactions) unfalsifiable, because the results may only depend on how the interaction is being modeled? This paper submits that in the case of SAT's interaction between self-control and morality, the two methods are not interchangeable from a substantive point of view as they both answer slightly different questions:

\section{Absolute Effects to Test the Condition of a Moral-filter Failure}

When testing the failed moral filter condition, we are interested in comparing the total amount of crime being reduced: The rationale is that more frequent moral-filter failures produce more criminogenic situations to control in total, because weak moral rules increase the likelihood to perceive crime as option. Thus, when moral rules are weak, we expect controls to come into play more often, so more crime can be reduced in total (regardless of the proportion this represents). Accordingly, the use of marginal effects is perfectly suitable to test SAT's condition of a moral-filter failure.

\section{Relative Effects to Test the Condition of Strong Moral Standards}

However, the total number of criminogenic situations that self-control was able to prevent from turning into crime is not of interest when SAT's conceptualization of self-control is being studied. Rather, the underlying research question is whether the effect is stronger because a more developed moral reason makes self-control more likely to succeed in cases where criminogenic situations are faced (regardless of how often those occur). Hence, stronger effects of self-control are not necessarily reflected in a reduction of more crime in total, but rather in the reduction of a higher proportion thereof (i.e., in a higher likelihood of success). Therefore, if we aim at testing the idea that self-control enforces moral standards, it is more appropriate to measure the effects of self-control in relative terms, thereby controlling for any differences in baseline crime.

In principle, these ideas also apply to comparisons of more than two groups in tests of nonlinear interactions. Applied to Kroneberg and Schulz' (2018) interpretation (Figs. 2(5) and 3(3)), absolute effects should be used when testing the dampening part of the nonlinear hypothesis based on SAT's condition of a failed moral filter (comparing medium and strong morality). In contrast, relative effects should be used when testing the enhancing part of the 
nonlinear hypothesis based on SAT's conceptualization of self-control (comparing low and medium morality).

\section{Further Notes on Previous Research}

Although not all of the studies addressing the interaction of self-control ability and morality have explicitly tested SAT, their implications for the theory can be assessed: We would expect that those studies that have used logged predictions (relative effects), and/or that have statistically controlled for setting criminogeneity, tend to deviate from the common finding of dampening interactions, because they were not designed to test self-control's failed moral filter condition.

This is however not always the case: Most studies have reported marginal effects and, in the case of significant interactions, find them to be stronger for lower levels of morality, among them even some studies that have controlled for setting criminogeneity (Higgins and Makin 2004; Schoepfer and Piquero 2006). Others, who have also controlled for setting criminogeneity, indeed find no interaction (Higgins 2005), or their coefficients even suggest stronger marginal effects of self-control ability for higher levels of morality (some analyses in Bruinsma et al. 2015). Only three studies are based on logged predictions, one of which also finds slight support for the expected enhanced interaction (some analyses in Antonaccio and Tittle 2008), whereas the other two still report stronger effects for lower levels of morality (Li 2004; Hirtenlehner 2015). In particular Li's (2004) results are at odds with SAT, as he has additionally controlled for setting criminogeneity.

Of those studies that have modeled more complex interactions by testing the effects of self-control ability contingent on combinations of individual and setting moral rules, none has used logged predictions (Eifler 2015; Pauwels 2018; Schepers and Reinecke 2018; Hirtenlehner and Leitgöb 2021; additional analyses in Higgins and Makin 2004). Apart from Eifler's (2015) somewhat unclear results, all of them reveal strongest effects when both, individual and setting moral rules encourage crime. This is not what SAT would predict, but is what we may expect considering that in this constellation the likelihood to face criminogenic situations is highest and thus marginal effects of self-control have the greatest chance to become visible.

Particularly intriguing is a study by Kammigan et al. (2019), who apply SAT to socially desirable responding in surveys. Their results show stronger absolute effects of self-control ability on the rule-breaking behavior of misreporting for lower levels of individual morality, but also for higher levels of morality if a different type of misreporting is the dependent variable. In both instances however (and also for other conditions being tested) are absolute effects of self-control stronger under conditions that increase the probability of misreporting: Low morality increases the probability to overreport drug use, while high morality increases the probability to deny drug use. This underlines the notion that effects of selfcontrol have at least a greater chance to become visible the more there is to control.

In summary, there is no clear pattern that supports or falsifies SAT's moral standards to enforce condition or the idea that dominant finding of dampening interactions is due to morality being correlated with setting rules. This paper will be testing these ideas more systematically. 


\section{Research Questions and Hypotheses}

It starts with a test of SAT's moral standards to enforce condition, from which follows that the effects of self-control should increase with increasing levels of morality. It was argued that a valid test of this hypothesis requires that the conditional effects of self-control are measured as proportional changes, which allow to compare the effects independently of the total amount of crime being reduced. The underlying mechanism implies that self-control should work better when morality is strong, although such actors with strong morality should carry little with them to be controlled: Socialization and self-selective processes decrease their likelihood to encounter criminogenic settings, in which they perceive crime as option. Out of those rare cases however, self-control should prevent a larger portion from turning into crime, i.e., should be more likely to succeed-as long as there remains something to be controlled at all.

Hypothesis 1 Testing SAT's conceptualization of self-control enforcing personal moral standards, stronger effects of self-control ability in relative terms are expected when morality increases: Self-control ability is expected to reduce a higher proportion of crime for those with higher levels of morality.

Actors with lower levels of morality, on the other hand, should find themselves in criminogenic settings more often, which provide more to be controlled. Self-control may thus reduce crime more often (larger absolute effects) — at least, as long as there remains a personal reason to exercise self-control. ${ }^{2}$ Thus, when testing SAT's moral-filter condition using individual morality as a proxy, we expect the interaction to be in line with most previous research:

Hypothesis 2 Testing SAT's assumption that a failure of the moral filter conditions the effect of controls, more pronounced effects of self-control ability in absolute terms are expected when morality decreases: Self-control ability is expected to reduce more crime in total for those with lower levels of morality.

However, the dampening interaction specified in Hypothesis 2 should be due to morality's positive correlation with setting rules and should thus vanish or be at least less pronounced after respondents' low risk of exposure to criminogenic settings is statistically controlled for. At the same time, adjustment should unveil the less biased, i.e., more accentuated, enhancing interaction specified in Hypothesis 1.

Hypothesis 3 After controlling for respondents' low risk of exposure to criminogenic settings, the interaction specified in Hypothesis 2 is less pronounced, while this is not the case for the interaction specified in Hypothesis 1.

\footnotetext{
${ }^{2}$ But even if low morality seems to leave no moral reason to exercise self-control, self-control ability might still be relevant to some extent: In some situations, actors may have judged specific criminal action alternatives as morally wrong despite their otherwise low values on the generalized morality measure that is used in many studies. Furthermore, self-control might be grounded on other than moral reasons: Outside the scope of SAT, it could be argued with Tittle et al.'s (2004) concept of the desire to exercise self-control that other cost factors may offer reasons even for actors who lack moral standards. A special cost factor within the scope of SAT are the deterrent cues of the situation, which become relevant just when morality is low: Wikström and Treiber (2007, pp. 249-250) propose that individuals with strong executive capabilities (selfcontrol ability) may be more sensitive to relevant deterrent cues. Self-control ability may thus indirectly decrease crime for those with low morality, because it makes deterrence easier.
} 


\section{Data and Measures}

Analyses will be based on data from the third wave of the International Self-Report Delinquency study (ISRD-3). The dataset consists of city-based (and some national) random samples of grade 7 to grade 9 school classes from (up to now) 28 countries $^{3}$. Interviews were conducted between, 2012 and, 2017, using paper-and-pencil questionnaires and computerized versions thereof, which were self-administered by the students in their classrooms. Countries' school access rates vary between $19 \%$ and $100 \%$, and student response rates within classes vary between $52 \%$ and 100\% (more details: Enzmann et al. 2018).

The dataset contains data from $n=66,395$ students. Grades are approximately equally distributed (about $32 \%$ grade 7 and 8 each, and 36\% grade 9), the students' age ranges from 12 to 16 years (percentiles 1 to 99 , mean $=13.8$ years, $\mathrm{SD}=1.1$ ), and $50.6 \%$ of the students are female ( $49.4 \%$ male).

\section{Dependent Variables}

Four last year frequency scores of self-reported offending will be analyzed: ${ }^{4}$ (1) total offending, containing shoplifting, burglary, car theft, car breaking, robbery/extortion, theft, assault, graffiti, vandalism, and drug dealing, (2) acquisitive offenses, containing shoplifting, burglary, car theft, car breaking, robbery/extortion, theft, and drug dealing, (3) violence, consisting of assault, and (4) non-acquisitive property offenses, containing graffiti and vandalism. All offenses were adjusted for outliers before summing them up: Values greater than 365 were set to missing, because they may indicate that students did not take the questions seriously. All other values crossing a threshold that defines outliers were adjusted separately in each country. ${ }^{5}$

\section{Independent Variables}

\section{Self-control Ability}

The capability for self-control was measured on a four-point Likert-scale derived from the items developed by Grasmick et al. (1993). Six items comprising the subdimensions of impulsivity and risk-taking were combined in an item mean score that was then scaled to a range from -1 to +1 , with higher values indicating higher levels of self-control ability (standardized Cronbach's $\alpha=0.794$; wording of items in appendix, Table 5).

\footnotetext{
3 Armenia, Austria, Belgium, Bosnia and Herzegovina, Cape Verde, Croatia, Czech Republic, Denmark, Estonia, Finland, France, Germany, India, Indonesia, Italy, Lithuania, North Macedonia, Netherlands, Poland, Portugal, Serbia, Slovakia, Switzerland, Turkey, UK, Ukraine, USA, Venezuela.

${ }^{4}$ All composite scores in this paper were created only for students who have provided valid information on at least two third of the associated items (except scores of only two items).

${ }^{5}$ Values with expected frequency $<0.5$ were defined as outliers, with the expected frequencies following a negative binomial distribution with mean and overdispersion parameter obtained from the empirical distribution of the offense in question. All outliers were replaced by randomly drawn numbers from the expected distribution (the original order was maintained, and new values must not be smaller than 10 , so they can be defined as being still high) (general description of the procedure: Enzmann 2015, 138-142).
} 


\section{Morality}

Five items derived from PADS+ (e.g., Wikström et al. 2012, 132-135) measure on a fourpoint Likert-scale how wrong students think it is for someone of their age to do each of the following: property damage, shoplifting, burglary, assault, and robbery/extortion. SAT's concept of action-relevant moral rules contains the notion that moral rules should relate to the specific action and circumstances in question to guide behavior in a specific situation (e.g., Wikström, 2010, 221-222). Corresponding to each type of offending, either all or only subsets of these items were used to create action-specific item mean scores: For morality related to total offending all five items were used $(\alpha=0.831)$; for morality related to acquisitive offenses shoplifting, burglary and robbery/extortion were used $(\alpha=0.746)$; violence-related morality consists of assault, and morality related to non-acquisitive property offenses consists of property damage. The scores were also scaled to a range from -1 to +1 with higher values indicating higher levels of morality.

\section{Control Variables}

The models will be presented without socio-demographic controls. From the viewpoint of SAT, the relevant proximal causes of crime (morality, self-control, and exposure to criminogenic settings) are being modeled, while socio-demographic characteristics are at best proxy measures of the more distal causes of the causes that should not exert direct effects. But supplementary analyses, which will only be referred to in the text, will test whether the results hold after adjusting for grade, gender, and deprivation (mean score of two sevenpoint items asking whether students' families are worse off than other families and whether students have less money to spend than others of their age).

\section{Absence of Social Desirability}

However, the relevant relationships might be confounded by respondents' tendency to answer dishonestly to sensitive questions (social desirability). Therefore, a control variable will be included based on the question: "Imagine you had used cannabis (cannabis/marijuana/hash), do you think that you would have said so in this questionnaire?" The answer categories were dichotomized, with "I have already said that I have used it", "definitely yes" and "probably yes" indicating honest responses (1), and "probably not" and "definitely not" indicating respondents who are not willing to admit potential cannabis use (0).

\section{Low Lifestyle Risk}

Two variables will be used to statistically control for a lack of students' risk of exposure to criminogenic settings: The first measures a low risk of unsupervised leisure time spent with peers, capturing opportunities and the probability of spending time in potentially criminogenic settings. Inspired by Steketee's (2012, p. 242) risky-lifestyle measure for ISRD-2 data, each of the indicators in Table 1 were first categorized into high (0), medium (0.5), and low lifestyle risk (1), and then combined into an item mean score $(\alpha=0.523)$. 
Table 1 Indicators for low lifestyle risk

\begin{tabular}{|c|c|c|c|}
\hline Indicator & 0 (high risk) & 0.5 (medium risk) & $\begin{array}{l}1 \text { (low } \\
\text { risk) }\end{array}$ \\
\hline Frequency of going out at night & $\begin{array}{l}3 \text { or more times per } \\
\text { week }\end{array}$ & 1-2 times per week & Never \\
\hline Spending most of free time with... & $\begin{array}{l}\text { Larger group of } \\
\text { friends }\end{array}$ & $\begin{array}{l}\text { Alone or with 1-3 } \\
\text { friends }\end{array}$ & Family \\
\hline $\begin{array}{l}\text { Frequency of hanging out at public places } \\
\text { like shopping centers, streets, park, or the } \\
\text { neighborhood just for fun }\end{array}$ & Often & Sometimes & Never \\
\hline Parental supervision $^{\mathrm{a}}$ & $\begin{array}{l}\text { Low }(<=25 \% \text { of } \\
\text { maximum possible } \\
\text { score })\end{array}$ & $\begin{array}{l}\text { Medium }(>25 \% \text { and } \\
<75 \% \text { of maximum pos- } \\
\text { sible score })\end{array}$ & $\begin{array}{l}\text { High } \\
(>=75 \% \\
\text { of maxi- } \\
\text { mum } \\
\text { possible } \\
\text { score })\end{array}$ \\
\hline
\end{tabular}

Table adapted from Steketee (2012, p. 242, Table 9.2)

${ }^{a}$ Mean score of eight items (wording in appendix, Table 5)

\section{No Delinquent Friends}

The second variable measures the lack of association with delinquent friends, capturing the moral content of those settings the actor is frequently exposed to. Students were asked whether they have friends that have committed each of the following offenses: shoplifting, burglary, robbery/extortion, and assault. Again, corresponding to each dependent variable, action-specific prevalence scores of having delinquent friends (0) or not (1) were created. Related to total offending, all four items were used; related to acquisitive offenses, a subset containing shoplifting, burglary, and robbery/extortion was used; and related to violence, the assault item was used. For non-acquisitive property offenses, there is no action-specific item available, so the most general measure containing all four items will be used.

\section{Analytic Strategy}

For robustness checks, the interaction of self-control ability and morality will be tested for the four offending measures separately. The frequency scores are overdispersed count variables (Table 2) that will be fitted by negative binomial regression models using Stata's (Version SE 15.1) - menberg-command, assuming the variance to be a function of the mean $\mu_{i j}$ and overdispersion parameter $\alpha$ (i.e., $\mu_{i j}+\alpha \mu_{i j}^{2}$ ). Where possible, weights (inverse of the probability of being sampled) will be applied. ${ }^{6}$

Interactions are modeled by including the product terms of self-control ability and morality, using multilevel models (Eq. (1)) for an overall test of the interaction within the 28 countries (subscript $j$ ). The models include only individual-level predictors, with fixed effects for covariates (...) and, for reasons of parsimony, a minimum set of random effects to mimic separate country analyses: random intercepts $\left(\beta_{0 j}\right)$ that vary around the grand mean $\left(\gamma_{00}\right)$, as well as random slopes of self-control $\left(\beta_{1 j}\right)$, morality $\left(\beta_{2 j}\right)$, and their product

\footnotetext{
${ }^{6}$ Weights are available for Austria, Finland, France, Germany, Netherlands, Poland, Portugal, Switzerland, Turkey, UK, USA.
} 
Table 2 Descriptive statistics for the pooled sample ( $n=28$ countries)

\begin{tabular}{lllrl}
\hline Variable & Min./Max. & Mean/Proportion & SD & Valid $n$ students \\
\hline Offending (total) & $0 / 1,306$ & 1.482 & 10.288 & 65,130 \\
Offending (acquisitive) & $0 / 986$ & 0.836 & 7.964 & 65,136 \\
Offending (violence) & $0 / 152$ & 0.090 & 1.598 & 64,939 \\
Offending (non-acquisitive) & $0 / 168$ & 0.562 & 2.883 & 65,148 \\
Self-control & $-1 / 1$ & 0.130 & 0.467 & 65,104 \\
Morality (total) & $-1 / 1$ & 0.761 & 0.321 & 65,565 \\
Morality (acquisitive) & $-1 / 1$ & 0.753 & 0.335 & 65,618 \\
Morality (violence) & $-1 / 1$ & 0.794 & 0.431 & 65,496 \\
Morality (non-acquisitive) & $-1 / 1$ & 0.752 & 0.421 & 65,491 \\
Low lifestyle risk & $0 / 1$ & 0.586 & 0.225 & 66,008 \\
No delinquent peers (total) & $0 / 1$ & 0.710 & 0.454 & 65,287 \\
No delinquent peers (acquisitive) & $0 / 1$ & 0.728 & 0.445 & 65,300 \\
No delinquent peers (violence) & $0 / 1$ & 0.929 & 0.257 & 65,367 \\
Would admit cannabis use & $0 / 1$ & 0.652 & 0.476 & 64,284
\end{tabular}

$\mathrm{SD}=$ standard deviation

$\left(\beta_{3 j}\right)$, which vary around the corresponding overall slopes $\left(\gamma_{10}, \gamma_{20}, \gamma_{30}\right)$. The errors of the random coefficients $u_{k j}$ have variances of $\tau_{k 0}$.

$$
\begin{gathered}
\eta_{i j}=\ln \left(\mu_{i j}\right)=\beta_{0}+\beta_{1 j}\left(\operatorname{Selfc}_{i j}\right)+\beta_{2 j}\left(\operatorname{Moral}_{i j}\right)+\beta_{3 j}\left(\operatorname{Self}_{i j} \operatorname{Moral}_{i j}\right)+\ldots+\varepsilon_{i j} \\
=\left(\gamma_{00}+u_{0 j}\right)+\left(\gamma_{10}+u_{1 j}\right) \operatorname{Selfc}_{i j}+\left(\gamma_{20}+u_{2 j}\right) \operatorname{Moral}_{i j}+\left(\gamma_{30}+u_{3 j}\right) \operatorname{Selfc}_{i j} \operatorname{Moral}_{i j}+\ldots+\varepsilon_{i j}
\end{gathered}
$$

\section{Modeling the Conditional Effects of Self-Control}

Proportional changes in offending counts for a one-unit change in self-control (semi-elasticities) evaluated at different levels of morality (interaction) will be reported to test Hypothesis 1 . As the linear predictions in negative binomial regressions are made on a log scale, the slopes for self-control $\left(\gamma_{10}\right)$ can already be interpreted as semi-elasticities (cf. e.g., Hilbe 2011, 129-130). The coefficients for the interaction term $\left(\gamma_{30}\right)$ then give the difference between semi-elasticities of self-control when morality changes by one unit, and will be presented in the regression tables. However, because of the nonlinear relationship between predictors and dependent variable, the slopes $\gamma$, being partial derivatives $((\partial \mu / \mu) / \partial x$ ), only approximate the proportional changes in offending counts $(\Delta \mu / \Delta x)$ when discrete one-unit increases in the predictors $(\Delta x)$ are not infinitesimally small (Eq. (2)). The approximation is only sufficiently accurate for small discrete changes in the predictor, for small slopes $(\leq|0.1|)$, and when the nonlinear count predictions resemble a straight line.

$$
\gamma=\frac{\left(\frac{\partial \mu}{\mu}\right)}{\partial x} \approx \frac{\left(\frac{\Delta \mu}{\mu}\right)}{\Delta x}
$$

A better approximation of the proportional change in offending counts for discrete changes in the predictors can be obtained by Eq. (3) (cf. e.g., Stocker 2014, 33-35). These estima- 
tors will be presented in the graphs illustrating the interaction, and their significance will be tested using Wald tests provided by Stata's - nlcom- command.

$$
\frac{\left(\frac{\Delta \mu}{\mu}\right)}{\Delta x}=e^{\gamma}-1=\text { IncidenceRateRatio }(\operatorname{IRR})-1
$$

Absolute changes in offending counts for a one-unit change in self-control (marginal effects) evaluated at different levels of morality (interaction) will be reported to test Hypothesis 2. However, because of the nonlinear relationship between predictors and dependent variable, the regression models predict as many marginal effects as there are combinations of covariates in the sample. Thus, average marginal effects (AME, Eq. (4)) of self-control, fixed at representative values of morality, will be predicted and their difference tested using Stata's -margins-command

$$
A M E=\hat{\gamma}_{10} \cdot \bar{\mu}_{i j}
$$

\section{Scaling Continuous Predictors}

These representative values were supposed to mark low and high morality. But because of the variable's skewness, the options of using one standard deviation (SD) below and above the mean, as well as of defining low and high morality at -0.5 and 0.5 have been ruled out: In the pooled sample, scores of $1 \mathrm{SD}$ above average morality exceed the scale's upper limit, students scoring $1 \mathrm{SD}$ below the average would still regard delinquent behavior as quite wrong (see Table 2), and values of -0.5 or lower are so rare that in some countries only single individuals exhibit low morality. The ISRD-3-samples thus join the previous studies, which Hirtenlehner and Reinecke $(2018$, p. 5) refer to as basically missing the group of deviant morality. As a consequence, the effects of self-control will be predicted for medium (0) and highest levels of morality (1), without any need to model nonlinear interactions.

In order to assure meaningful interpretations of the regression coefficients, morality and low lifestyle risk will be entered into the models on their original scales, morality will be additionally centered at its grand mean, and all other continuous predictors will be $z$-standardized (centered at their grand means) and divided by $2 .^{7}$

\section{Comparing Coefficients Across Models/Groups}

For tests of Hypothesis 3, analyses will be run with and without statistically controlling for respondents' low risk of exposure to criminogenic settings. However, the regression coefficients of nonlinear models are not directly comparable between such nested models: Adding variables may lead to a change of the total variance (i.e., to a change of the scale of an assumed underlying latent variable that is predicted by the linear part of the regression equation) and thus to a change of the coefficients, even if the added variables are uncorrelated with the other predictors Mood 2010; Hox 2010, 157-158). Hence, the change of a

\footnotetext{
${ }^{7}$ One-unit changes in the $\mathrm{z} / 2$-standardized predictors correspond to changes of two standard deviations (see Gelman 2008).
} 
coefficient after adding control variables is not necessarily due to a correlation with control variables.

Karlson et al. (2012) have developed a method for logit and probit models to isolate that part of the change that is indeed due to a correlation with controls. Implementing their approach, the reduced model without controls will also include the part of low exposure risk that is uncorrelated with all other predictors (i.e., the residuals from a regression of low exposure risk on all other predictors). Any change of the coefficients caused by adding the residuals can have only arisen from rescaling. In a second model, the residuals will be replaced by low exposure risk. Any change of the coefficients can now only result from a correlation with low exposure risk. This procedure can be thought of adjusting the coefficients of the reduced model (without controls, measuring total effects) to the scale of the full model (including the controls). The drawback is that the total effects in the reduced models differ according to the set of control variables that is being assessed.

There is some disagreement on whether rescaling is also a problem when comparing coefficients of the same model between groups (e.g., between levels of morality) (see e.g., Mood 2010; Kuha and Mills 2020). This paper adopts Kuha and Mills' (2020) rationale for logistic regression, that this is only a problem when the (unobserved) predictions estimated by the linear part of the model are "regarded not as convenient piece of mathematical fiction but as a real variable of interest." (2020, p. 506) This is not the case here, as the (observable) crime counts are of interest and not any underlying (unobserved) property predicted by the linear part of the regression equation. The linear predictions are only important in that they provide the mathematical tool for estimating the proportional change in crime counts.

\section{Results}

Tables 3 and 4 present results of multilevel negative binomial regressions testing the interaction between self-control ability and morality within countries. ${ }^{8}$

\section{Hypotheses 1 and 2: Not Adjusted for Low Exposure Risk}

Tests of Hypothesis 1 using relative effects of self-control reveal significant interactions for all dependent variables except for violence, regardless of whether they are approximated by the coefficients of the product terms (Table 3) or by the improved estimates given in the upper row of Fig. 4. The associated graphs illustrate semi-elasticities of self-control by presenting the predicted values for medium (solid line) and high (dashed line) morality on a log scale. They show that for the remaining three dependent variables, self-control reduces a significantly higher proportion of crime for those with higher levels of morality (although not significant, this direction can be also observed for violence).

\footnotetext{
${ }^{8}$ The interaction in the models for violence and non-acquisitive offenses was not allowed to vary between countries, because otherwise the models did not converge. Since results for the remaining models that actually did converge despite including the random product term were reasonably similar to the results for corresponding models without the random product (results not presented), it appears adequate to omit the random product.
} 
Table 3 Not adjusted for low exposure risk: Results of multilevel negative binomial regressions of selfreported offending frequency on self-control, morality, and their interaction

\begin{tabular}{|c|c|c|c|c|c|c|c|c|}
\hline \multirow[b]{2}{*}{ Fixed effects } & \multicolumn{2}{|c|}{ Total Offending } & \multicolumn{2}{|c|}{ Acquisitive Offenses } & \multicolumn{2}{|l|}{ Violence } & \multicolumn{2}{|c|}{$\begin{array}{l}\text { Non-Acquisitive } \\
\text { Offenses }\end{array}$} \\
\hline & $\hat{y}$ & $\mathrm{AME}^{\mathrm{a}}$ & $\hat{y}$ & $\mathrm{AME}^{\mathrm{a}}$ & $\hat{y}$ & $\mathrm{AME}^{\mathrm{a}}$ & $\hat{y}$ & $\mathrm{AME}^{\mathrm{a}}$ \\
\hline \multirow[t]{2}{*}{ Self-control $(z / 2)$} & $-1.537^{* * *}$ & $-1.998^{* * *}$ & $-1.661^{* * *}$ & $-0.979^{* * *}$ & $-1.932^{* * *}$ & $-0.158^{* *}$ & $-1.698^{* * *}$ & $-0.913^{* * *}$ \\
\hline & $(0.084)$ & $(0.245)$ & $(0.145)$ & $(0.170)$ & $(0.241)$ & $(0.045)$ & $(0.091)$ & $(0.096)$ \\
\hline \multirow[t]{2}{*}{ Morality (centered) } & $-2.026^{* * *}$ & $-2.706^{* * *}$ & $-2.176^{* * *}$ & $-1.357^{* * *}$ & $-1.548^{* * *}$ & $-0.127^{* * *}$ & $-1.003^{* * *}$ & $-0.490^{* * *}$ \\
\hline & $(0.109)$ & $(0.314)$ & $(0.178)$ & $(0.239)$ & $(0.192)$ & $(0.025)$ & $(0.102)$ & $(0.047)$ \\
\hline \multirow[t]{2}{*}{ Self-c. ${ }^{*}$ morality } & $-0.443^{* *}$ & $3.984^{* * *}$ & $-0.508^{*}$ & $2.000^{* * *}$ & -0.223 & $0.197^{* * *}$ & $-0.318^{*}$ & $0.682^{* * *}$ \\
\hline & $(0.153)$ & $(0.773)$ & $(0.252)$ & $(0.515)$ & $(0.263)$ & $(0.055)$ & $(0.145)$ & $(0.142)$ \\
\hline \multirow{2}{*}{$\begin{array}{l}\text { Low lifestyle risk } \\
\text { (residuals) }\end{array}$} & $-2.315^{* * *}$ & $-3.442^{* * *}$ & $-2.143^{* * *}$ & $-1.509^{* * *}$ & $-2.008^{* * *}$ & $-0.181^{* *}$ & $-2.560^{* * *}$ & $-1.461^{* * *}$ \\
\hline & $(0.123)$ & $(0.336)$ & $(0.196)$ & $(0.219)$ & $(0.383)$ & $(0.053)$ & $(0.135)$ & $(0.185)$ \\
\hline \multirow{2}{*}{$\begin{array}{l}\text { No delinquent peers } \\
\text { (residuals) }\end{array}$} & $-1.066^{* * *}$ & $-1.586 * *$ & $-1.303^{* * *}$ & $-0.917^{* * *}$ & $-1.869^{* * *}$ & $-0.168^{* * *}$ & $-0.976^{* * *}$ & $-0.557^{* * *}$ \\
\hline & $(0.069)$ & $(0.186)$ & $(0.103)$ & $(0.132)$ & $(0.185)$ & $(0.035)$ & $(0.055)$ & $(0.072)$ \\
\hline \multirow[t]{2}{*}{ Would admit (0/1) } & 0.120 & 0.179 & $0.234 *$ & 0.165 & -0.182 & -0.016 & 0.092 & 0.053 \\
\hline & $(0.071)$ & $(0.112)$ & $(0.115)$ & $(0.086)$ & $(0.204)$ & $(0.020)$ & $(0.061)$ & $(0.036)$ \\
\hline \multirow[t]{2}{*}{ Intercept } & $-0.701^{* * *}$ & & $-1.732^{* * *}$ & & $-3.812^{* * *}$ & & $-1.482^{* * *}$ & \\
\hline & $(0.100)$ & & $(0.156)$ & & $(0.197)$ & & $(0.132)$ & \\
\hline \multicolumn{9}{|l|}{ Random effects } \\
\hline \multirow[t]{2}{*}{$\hat{\tau}_{10}$ Self-control } & $0.168^{* *}$ & & $0.524^{* *}$ & & $1.042^{*}$ & & $0.174^{* *}$ & \\
\hline & $(0.062)$ & & $(0.189)$ & & $(0.429)$ & & $(0.057)$ & \\
\hline \multirow[t]{2}{*}{$\hat{\tau}_{20}$ Morality } & $0.231^{* *}$ & & $0.743^{*}$ & & 0.218 & & 0.191 & \\
\hline & $(0.076)$ & & $(0.296)$ & & $(0.112)$ & & $(0.112)$ & \\
\hline \multirow[t]{2}{*}{$\hat{\tau}_{30}$ Self-c. ${ }^{*}$ Morality } & 0.364 & & $1.377^{*}$ & & - & & - & \\
\hline & $(0.216)$ & & $(0.692)$ & & & & & \\
\hline \multirow[t]{2}{*}{$\hat{\tau}_{00}$ Intercept } & $0.224^{* *}$ & & $0.359^{* * *}$ & & $0.514^{*}$ & & $0.496^{* * *}$ & \\
\hline & $(0.084)$ & & $(0.086)$ & & $(0.203)$ & & $(0.108)$ & \\
\hline \multirow[t]{2}{*}{$\operatorname{In}(\alpha)$} & $1.990^{* * *}$ & & $2.519^{* * *}$ & & $4.049^{* * *}$ & & $2.175^{* * *}$ & \\
\hline & $(0.083)$ & & $(0.126)$ & & $(0.213)$ & & $(0.082)$ & \\
\hline \multirow[t]{2}{*}{ Predicted mean ${ }^{\mathrm{b}}$} & $1.766^{* * *}$ & & 1.852 & & $0.118^{* * *}$ & & $0.688^{* * *}$ & \\
\hline & $(0.228)$ & & $(2.079)$ & & $(0.021)$ & & $(0.074)$ & \\
\hline Valid $n$ & 62,592 & & 62,635 & & 62,451 & & 62,487 & \\
\hline
\end{tabular}

${ }^{*} p<0.05,{ }^{* *} p<0.01,{ }^{* * *} p<0.001$; standard errors (delta method) in parentheses; covariances of random effects not presented, weighted data; $n$ countries $=28$

a AMEs based on fixed effects only; interaction: difference of counterfactual AMEs of self-control at medium (0) and high (1) morality

${ }^{\mathrm{b}}$ Based on fixed and random effects

When the effects of self-control are instead reported as AMEs for a test of Hypothesis 2, self-control reduces significantly more crime for lower levels of morality for all dependent variables (Table 3 and upper row of Fig. 5).

\section{Hypothesis 3: Adjusted for Low Exposure Risk}

After statistically controlling for students' low risk of exposure to criminogenic settings (Table 4), the differences of the AMEs of self-control between the two levels of moral- 
Table 4 Adjusted for low exposure risk: Results of multilevel negative binomial regressions of self-reported offending frequency on self-control, morality, and their interaction

\begin{tabular}{|c|c|c|c|c|c|c|c|c|}
\hline \multirow[b]{2}{*}{ Fixed effects } & \multicolumn{2}{|c|}{ Total Offending } & \multicolumn{2}{|c|}{ Acquisitive Offenses } & \multicolumn{2}{|l|}{ Violence } & \multicolumn{2}{|c|}{$\begin{array}{l}\text { Non-Acquisitive } \\
\text { Offenses }\end{array}$} \\
\hline & $\hat{y}$ & $\mathrm{AME}^{\mathrm{a}}$ & $\hat{y}$ & $\mathrm{AME}^{\mathrm{a}}$ & $\hat{y}$ & $\mathrm{AME}^{\mathrm{a}}$ & $\hat{y}$ & $\mathrm{AME}^{\mathrm{a}}$ \\
\hline Self-control $(z / 2)$ & $\begin{array}{l}-1.087^{* * *} \\
(0.083)\end{array}$ & $\begin{array}{l}-1.334^{* * *} \\
(0.199)\end{array}$ & $\begin{array}{l}-1.195^{* * *} \\
(0.146)\end{array}$ & $\begin{array}{l}-0.648^{* * *} \\
(0.148)\end{array}$ & $\begin{array}{l}-1.554^{* * *} \\
(0.232)\end{array}$ & $\begin{array}{l}-0.116^{* *} \\
(0.037)\end{array}$ & $\begin{array}{l}-1.192^{* * *} \\
(0.096)\end{array}$ & $\begin{array}{l}-0.620^{* * *} \\
(0.069)\end{array}$ \\
\hline Morality (centered) & $\begin{array}{l}-1.498^{* * *} \\
(0.108)\end{array}$ & $\begin{array}{l}-1.927^{* * *} \\
(0.252)\end{array}$ & $\begin{array}{l}-1.683^{* * *} \\
(0.175)\end{array}$ & $\begin{array}{l}-1.007^{* * *} \\
(0.201)\end{array}$ & $\begin{array}{l}-1.251^{* * *} \\
(0.209)\end{array}$ & $\begin{array}{l}-0.094^{* * *} \\
(0.019)\end{array}$ & $\begin{array}{l}-0.728^{* * *} \\
(0.106)\end{array}$ & $\begin{array}{l}-0.327^{* * *} \\
(0.044)\end{array}$ \\
\hline Self-c.*morality & $\begin{array}{l}-0.435^{* *} \\
(0.152)\end{array}$ & $\begin{array}{l}1.303^{* *} \\
(0.467)\end{array}$ & $\begin{array}{l}-0.517^{*} \\
(0.251)\end{array}$ & $\begin{array}{l}0.702^{*} \\
(0.342)\end{array}$ & $\begin{array}{l}-0.334 \\
(0.262)\end{array}$ & $\begin{array}{l}0.091^{* *} \\
(0.035)\end{array}$ & $\begin{array}{l}-0.341^{*} \\
(0.145)\end{array}$ & $\begin{array}{l}0.177 \\
(0.122)\end{array}$ \\
\hline $\begin{array}{l}\text { Low lifestyle risk } \\
(0-1)\end{array}$ & $\begin{array}{l}-2.315^{* * *} \\
(0.123)\end{array}$ & $\begin{array}{l}-3.442^{* * *} \\
(0.336)\end{array}$ & $\begin{array}{l}-2.143^{* * *} \\
(0.196)\end{array}$ & $\begin{array}{l}-1.509^{* * *} \\
(0.219)\end{array}$ & $\begin{array}{l}-2.008^{* * *} \\
(0.383)\end{array}$ & $\begin{array}{l}-0.181^{* *} \\
(0.053)\end{array}$ & $\begin{array}{l}-2.560^{* * *} \\
(0.135)\end{array}$ & $\begin{array}{l}-1.461^{* * *} \\
(0.185)\end{array}$ \\
\hline $\begin{array}{l}\text { No delinquent } \\
\text { peers }(0 / 1)\end{array}$ & $\begin{array}{l}-1.066^{* * *} \\
(0.069)\end{array}$ & $\begin{array}{l}-1.586^{* * *} \\
(0.186)\end{array}$ & $\begin{array}{l}-1.303^{* * *} \\
(0.103)\end{array}$ & $\begin{array}{l}-0.917^{* * *} \\
(0.132)\end{array}$ & $\begin{array}{l}-1.869^{* * *} \\
(0.185)\end{array}$ & $\begin{array}{l}-0.168^{* * *} \\
(0.035)\end{array}$ & $\begin{array}{l}-0.976^{* * *} \\
(0.055)\end{array}$ & $\begin{array}{l}-0.557^{* * *} \\
(0.072)\end{array}$ \\
\hline Would admit $(0 / 1)$ & $\begin{array}{l}0.034 \\
(0.070)\end{array}$ & $\begin{array}{l}0.050 \\
(0.106)\end{array}$ & $\begin{array}{l}0.140 \\
(0.114)\end{array}$ & $\begin{array}{l}0.099 \\
(0.082)\end{array}$ & $\begin{array}{l}-0.224 \\
(0.205)\end{array}$ & $\begin{array}{l}-0.020 \\
(0.020)\end{array}$ & $\begin{array}{l}0.011 \\
(0.061)\end{array}$ & $\begin{array}{l}0.006 \\
(0.035)\end{array}$ \\
\hline Intercept & $\begin{array}{l}1.511^{* * *} \\
(0.097)\end{array}$ & & $\begin{array}{l}0.578^{* *} \\
(0.192)\end{array}$ & & $\begin{array}{l}-0.834^{*} \\
(0.357)\end{array}$ & & $\begin{array}{l}0.807^{* * *} \\
(0.173)\end{array}$ & \\
\hline Random effects & & & & & & & & \\
\hline$\hat{\tau}_{10}$ Self-control & $\begin{array}{l}0.168^{* *} \\
(0.062)\end{array}$ & & $\begin{array}{l}0.524^{* *} \\
(0.189)\end{array}$ & & $\begin{array}{l}1.042^{*} \\
(0.429)\end{array}$ & & $\begin{array}{l}0.174^{* *} \\
(0.057)\end{array}$ & \\
\hline$\hat{\tau}_{20}$ Morality & $\begin{array}{l}0.231^{* *} \\
(0.076)\end{array}$ & & $\begin{array}{l}0.743^{*} \\
(0.296)\end{array}$ & & $\begin{array}{l}0.218 \\
(0.112)\end{array}$ & & $\begin{array}{l}0.191 \\
(0.112)\end{array}$ & \\
\hline$\hat{\tau}_{30}$ Self-c. ${ }^{*}$ Morality & $\begin{array}{l}0.364 \\
(0.216)\end{array}$ & & $\begin{array}{l}1.377^{*} \\
(0.692)\end{array}$ & & - & & - & \\
\hline$\hat{\tau}_{00}$ Intercept & $\begin{array}{l}0.224^{* *} \\
(0.084)\end{array}$ & & $\begin{array}{l}0.359^{* * *} \\
(0.086)\end{array}$ & & $\begin{array}{l}0.514^{*} \\
(0.203)\end{array}$ & & $\begin{array}{l}0.496^{* * *} \\
(0.107)\end{array}$ & \\
\hline $\operatorname{In}(\alpha)$ & $\begin{array}{l}1.990^{* * *} \\
(0.083)\end{array}$ & & $\begin{array}{l}2.519^{* * *} \\
(0.126)\end{array}$ & & $\begin{array}{l}4.049^{* * *} \\
(0.213)\end{array}$ & & $\begin{array}{l}2.175^{* * *} \\
(0.082)\end{array}$ & \\
\hline Predicted mean ${ }^{\mathrm{b}}$ & $\begin{array}{l}1.766^{* * *} \\
(0.228)\end{array}$ & & $\begin{array}{l}1.852 \\
(2.079)\end{array}$ & & $\begin{array}{l}0.118^{* * *} \\
(0.021)\end{array}$ & & $\begin{array}{l}0.688^{* * *} \\
(0.074)\end{array}$ & \\
\hline Valid $n$ & 62,592 & & 62,635 & & 62,451 & & 62,487 & \\
\hline
\end{tabular}

${ }^{*} p<0.05,{ }^{* *} p<0.01,{ }^{* * *} p<0.001$; standard errors (delta method) in parentheses; covariances of random effects not presented, weighted data; $n$ countries $=28$

a AMEs based on fixed effects only; interaction: difference of counterfactual AMEs of self-control at medium (0) and high (1) morality

${ }^{\mathrm{b}}$ Based on fixed and random effects

ity become considerably smaller, i.e., the interactions become less pronounced. However, except for non-acquisitive property offenses, all interactions remain significant, with selfcontrol still reducing more crime for lower levels of morality (bottom row of Fig. 5).

The significant differences between semi-elasticities of self-control even increase after adjusting for low exposure risk, if the improved estimates $\left(e^{\gamma}-1\right)$ are used (Fig. 4), otherwise there seems to be not much change (Table 4). The exception is again violence, for which the interaction remains insignificant. For the other three dependent variables, self- 


\section{Predictions of Self-Reported Offending (Log Scale)}

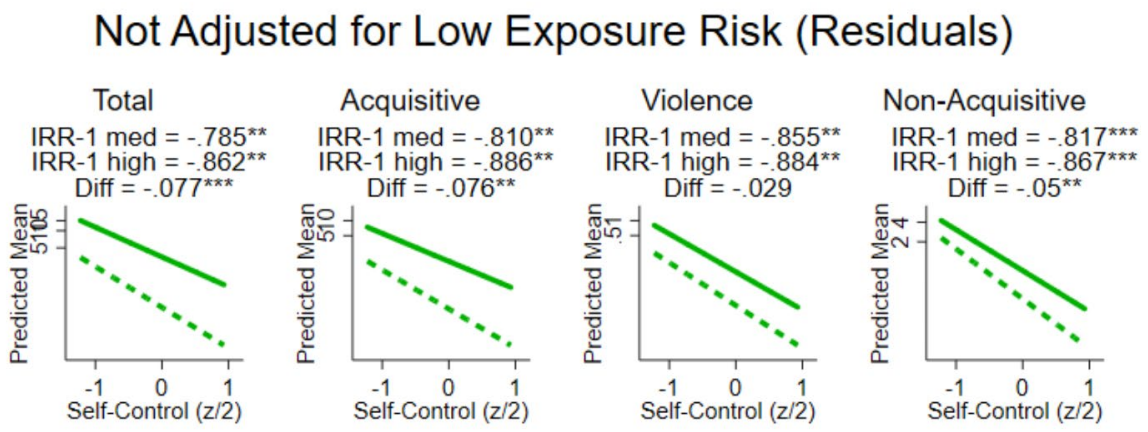

Adjusted for Low Exposure Risk

Total

IRR-1 med $=-.663^{* *}$ IRR-1 high $=-.782^{\star \star}$

Diff $=-119^{\star \star *}$

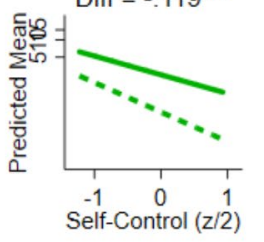

Acquisitive

IRR-1 med $=-.697^{* *}$

IRR-1 high $=-819^{\star \star}$

Diff $=-.122^{* \star}$

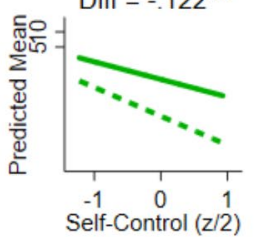

Violence

IRR-1 med $=-.789^{* *}$

IRR-1 high $=-.849^{\star \star}$

Diff $=-.06$

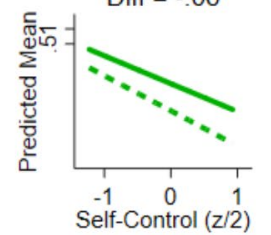

Non-Acquisitive

IRR-1 med $=-.696^{* * *}$

IRR-1 high $=-.784^{* * *}$

Diff $=-.088^{\star \star}$

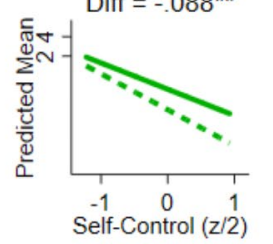

Notes:

Predictive margins at fixed values of self-control and morality. Predictions based on fixed effects only. Weighted data.

Significance testing: Wald Tests (Stata's -testnl- postestimation command).

Range of $x$-axis (self-control) from min. to max.

Fig. 4 Self-reported offending predicted by self-control at medium and high morality (logged predictions, based on the models in Tables 3 and 4)

control still reduces a higher proportion of crime when morality is high (bottom row of Fig. 4).

Supplementary analyses (results not presented in detail) show similar changes of the interactions measured in absolute and relative terms when adjusting for the interaction of low exposure risk and self-control instead of just using low exposure risk. ${ }^{9}$ Moreover, all

\footnotetext{
${ }^{9}$ However, after adjusting for the interaction, the difference between AMEs for non-acquisitive property offenses remains significant, and the differences between semi-elasticities only increase when the improved estimates are used, otherwise they lose significance.
} 


\section{Predictions of Self-Reported Offending}

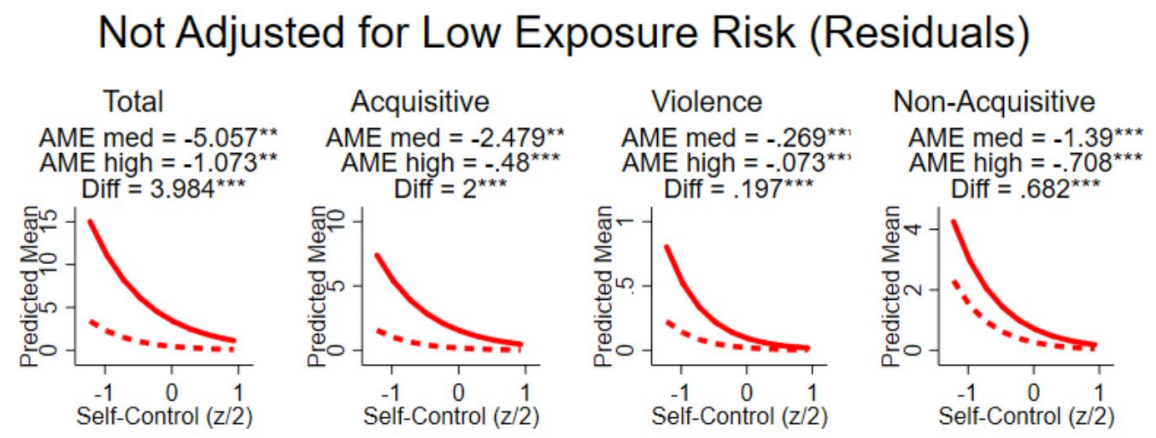

\section{Adjusted for Low Exposure Risk}
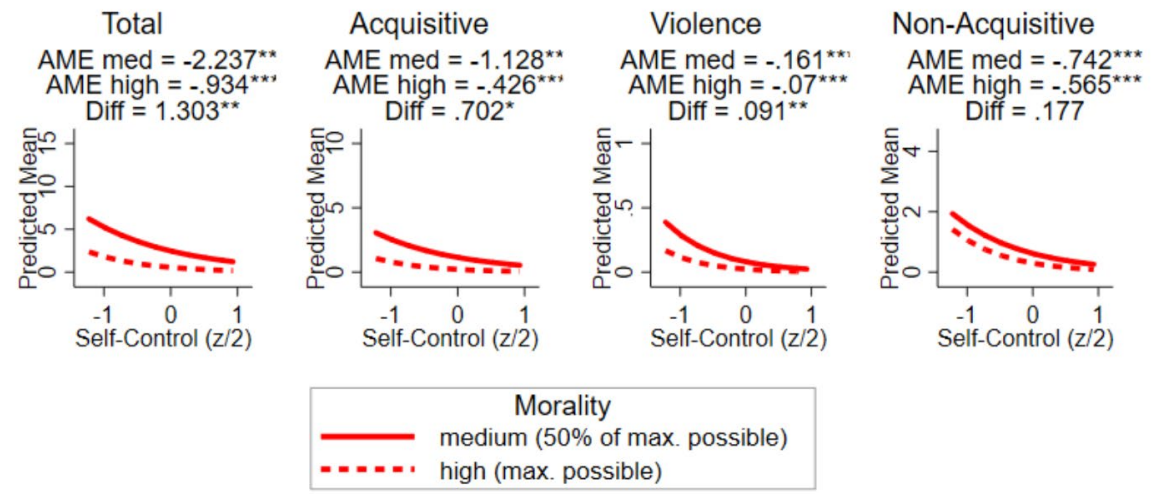

Notes:

Predictive margins at fixed values of self-control and morality. Predictions based on fixed effects only. Weighted data.

Range of $x$-axis (self-control) from min. to max.

Fig. 5 Self-reported offending predicted by self-control at medium and high morality (predictions based on the models in Tables 3 and 4)

relationships mentioned in the results section basically hold when accounting for grade, gender, and deprivation. ${ }^{10}$

\section{Discussion and Conclusion}

At the beginning, the question was raised how SAT can lead us to expect morality enhancing and dampening the effects of self-control at the same time, and whether this renders SAT unfalsifiable.

${ }^{10}$ However, the models for violence did not converge. 


\section{Implications for (Testing) SAT}

A logical inconsistency between passages in older publications and the current formulation of SAT was identified that would indeed render a part of the theory inherently unfalsifiable: Contradictory assumptions, about whether individuals holding very strong moral standards are susceptible to self-control relevant setting influences, lead to contradictory predictions for the effects of self-control when morality increases from medium to very strong. It was however suspected that the ambiguity is due to the theory's development over the years. As a consequence, the paper proposes to keep only the recent prediction of morality enhancing the effects of self-control ability. So most likely, the theory is not unfalsifiable in itself, although some clarification by its founders would help.

However, the recent prediction appears to be contradicted by most research, finding that morality dampens the effects of self-control. Yet for methodological reasons, the findings can still be interpreted in line with SAT without necessarily falsifying the assumption that self-control is enhanced by the required intact moral standards.

One reason can be traced back to the idea that measures of individual morality may capture several conditions for self-control, each of which is expected to moderate the effects of self-control in a different way: Obviously, measures of morality directly measure the concept of individual morality, higher levels of which should enhance effects of self-control. However, because of a correlation with setting rules, high levels of morality may also capture an intact (setting) moral filter (and perhaps the likelihood of habitual action), which should dampen effects of self-control, at least in comparison to medium morality. Interpreting the common finding of dampening interactions as being due to morality's correlation with setting rules does not necessarily prove the unbiased interaction wrong.

The paper brought up a further issue. Depending on whether the conditional effects of self-control are being modeled in absolute or relative terms, analyses tend to produce either dampening or enhancing interactions. While most researchers have modeled the conditional effects of self-control in absolute terms and find support for their hypothesis of dampening interactions, this does not necessarily exclude the chance that the alternative use of relative effects would have produced enhancing interactions.

The possibilities to interpret opposing interactions ex post in line with SAT and to channel results into the desired direction seem to pose serious validity threats. But what at a first glance appears to challenge SAT's falsifiability in an empirical sense rather calls for careful modeling decisions to enable valid tests of the theory: First, alternative explanations must be ruled out, for example, by not using proxy measures of the concepts of interest and/or by testing the influence of necessary statistical controls. Second, the choice of the type of conditional effect of self-control must be based on the substantive research question. While the commonly reported absolute (marginal) effects are suitable to test SAT's failed moral-filter condition, the paper proposes that tests of SAT's conceptualization of self-control require effects to be reported as proportional changes. Of course, the decision for one or the other becomes less straightforward when measures combine the conditions or when more complex interactions are being modeled.

\section{Key Empirical Findings}

In its empirical part, the paper has tested SAT's moral standards to enforce condition (Hypothesis 1) by expressing the conditional effects of self-control ability as proportional 
changes (semi-elasticities). The expectations are largely supported by the data, which reveal that higher levels of morality indeed enhance semi-elasticities of self-control—unless violence is the dependent variable, for which the effects of self-control and morality do not significantly depend on each other.

When expressing the conditional effects of self-control ability as AMEs for a test of the failed moral filter condition, the dominant pattern across all countries quite clearly shows that morality dampens the effects of self-control (as expected in Hypothesis 2), thereby replicating the most frequent finding of previous research. After adjusting for what individual morality and low exposure risk have in common, the interactions become considerably less pronounced. In line with Hypothesis 3, this finding implies that self-control ability has at least partially interacted with the portion of individual morality that measures the moral rules of the setting. However, even after adjusting, the interactions are still there (except for non-acquisitive property offenses), which may be due to an imperfect measure of those setting moral rules the students were situationally exposed to.

Also supporting Hypothesis 3, the significant differences in semi-elasticities of self-control ability do not change much or become even more accentuated after adjusting. Overall, modeling relative effects appears to be more important than adjustment to detect the proposed enhancing interaction.

\section{Limitations}

The results also allow for an alternative interpretation that is in line with the theory: Evidently, the impulsivity subdimension of the self-control scale based on the Grasmick et al. (1993) items also captures respondents' tendency for less deliberate action. Although SAT makes an analytical difference between self-control and deliberation (Wikström and Treiber $2007,255)$, it might not be possible to separate the two empirically within the impulsivity subscale. Measures of impulsivity have even been applied within a dual systems perspective to measure more automatic processes of decision-making (e.g., Thomas and McGloin 2013). If we now treat self-control ability (instead of morality) as the moderator variable, absolute effects of morality would be stronger for lower self-control ability (more impulsivity). This may indicate that for those who tend to act out of habit, the effect of the personal moral filter is more visible, perhaps because other factors like controls do not play a role in habitual action. On the other hand, relative effects of morality would be stronger for higher self-control ability (less impulsivity), which may indicate that for those who tend to deliberate, crime relies more strongly on a personal moral reason to exercise self-control.

On its downside, such an alternative interpretation is associated with a further validity problem of the predictors. Moreover, morality and self-control ability have not yet been tested for measurement invariance across all ISRD-3 countries. Another limitation is the problem of causal inference resulting from the cross-sectional nature of the ISRD-3 data, which include retrospective measures of the dependent variables, while the relevant predictors have been measured at the time of the interview. Not least, this study suffers from the fact that, due to the data structure, the units of analysis are individuals and not events, although the perception-choice processes leading to single events were of primary interest.

What we probably need, beyond the experimental analyses suggested by Kroneberg and Schulz (2018, p. 72), might be more qualitatively oriented research revealing insights into the mechanisms of the perception-choice process. 


\section{What Can Be Learned?}

In summary, SAT's assumption on the relationship between the effects of self-control and morality would benefit from a clarification by its founders, as well as other assumptions would do, e.g., on the relationship between moral correspondence and habitual action. Other than that, the clarity of the theory's assumptions might at times mask the complexity of their interrelations, which may be hard to disentangle empirically. But that just forces researchers to model their analyses very carefully.

In particular, the paper has demonstrated that logging the dependent variable in linear regression is more than a remedy to reduce its skewness, and that the use of negative binomial regression is more than a model that accounts for the functional form of the data. Such procedures also provide a different, and sometimes more appropriate interpretation of effects, which even makes some research questions testable at all. In this regard, the paper may advance our understanding of the interaction between self-control and morality in SAT and of empirical tests thereof. But it may have also raised some more questions on this issue, especially when more complex interactions combining the conditions for self-control are being modeled, in particular in the form of threeway-interactions between self-control ability, morality, and setting rules. The empirical role of self-control in the missing deviant morality group also remains an open question. Closing by borrowing the words of Hirtenlehner and Reinecke once more, there is still "[...] a whiff of ambiguity [that] remains. Resolving this dissonance in future works is highly advisable.” (2018, p. 5).

\section{Appendix}

Table 5 Items measuring self-control and parental supervision

\begin{tabular}{|c|c|}
\hline Self-control & Parental supervision \\
\hline $\begin{array}{l}\text { I act on the spur of the moment without stopping to } \\
\text { think. }\end{array}$ & My parents know where I am when I go out. \\
\hline $\begin{array}{l}\text { I do whatever brings me pleasure here and now, even at } \\
\text { the cost of some distant goal. }\end{array}$ & $\begin{array}{l}\text { My parents know what I am doing when I go } \\
\text { out. }\end{array}$ \\
\hline $\begin{array}{l}\text { I'm more concerned with what happens to me in the } \\
\text { short run than in the long run. }\end{array}$ & $\begin{array}{l}\text { My parents know what friends I am with when } \\
\text { I go out. }\end{array}$ \\
\hline $\begin{array}{l}\text { I like to test myself every now and then by doing some- } \\
\text { thing a little risky. }\end{array}$ & $\begin{array}{l}\text { If I have been out, my parents ask me what I } \\
\text { did, where I went, and who I spent time with. }\end{array}$ \\
\hline Sometimes I will take a risk just for the fun of it. & $\begin{array}{l}\text { If I go out in the evening my parents tell me } \\
\text { when I have to be back home by. }\end{array}$ \\
\hline \multirow[t]{3}{*}{$\begin{array}{l}\text { Excitement and adventure are more important to me } \\
\text { than security. }\end{array}$} & $\begin{array}{l}\text { If I am out and it gets late I have to call my } \\
\text { parents and let them know. }\end{array}$ \\
\hline & My parents check if I have done my homework. \\
\hline & $\begin{array}{l}\text { My parents check that I only watch films/DVDs } \\
\text { allowed for my age-group. }\end{array}$ \\
\hline $\begin{array}{l}1=\text { agree fully, } 2=\text { agree somewhat, } 3=\text { disagree some- } \\
\text { what, } 4=\text { disagree fully }\end{array}$ & $\begin{array}{l}1=\text { never, } 2=\text { seldom, } 3=\text { sometimes, } 4=\text { often, } \\
5=\text { almost always }\end{array}$ \\
\hline
\end{tabular}

Acknowledgements I would like to thank the anonymous reviewers for shifting the focus of this paper to a more valuable perspective. Your thoughtful and constructive comments were highly appreciated.

Funding The ISRD-3 study in Germany, France, The Netherlands, UK, and the US was made possible through the following grants, made under the Open Research Area (ORA) Program: German Research 
Foundation (DFG): Grant EN 490/1-1 (Germany), Agence Nationale de Recherche (ANR): Grant ANR13-ORAR-0005-01 (France), Netherlands Organisation for Scientific Research (NWO): Grant 464-13115 (Netherlands), Economic and Social Research Council (ESRC): Grant ES/L016656/1 (UK), National Science Foundation (NSF): Grant 1419588 (US).

\section{Open Access funding enabled and organized by Projekt DEAL.}

Data Availability The ISRD-3 dataset is not yet publicly available due to ongoing data merging and cleaning processes, but will be publicly available in the near future. A reduced dataset, generated and analyzed during the current study, is available from the author on reasonable request.

\section{Declarations}

Conflict of Interest The author declares no conflict of interest.

Open Access This article is licensed under a Creative Commons Attribution 4.0 International License, which permits use, sharing, adaptation, distribution and reproduction in any medium or format, as long as you give appropriate credit to the original author(s) and the source, provide a link to the Creative Commons licence, and indicate if changes were made. The images or other third party material in this article are included in the article's Creative Commons licence, unless indicated otherwise in a credit line to the material. If material is not included in the article's Creative Commons licence and your intended use is not permitted by statutory regulation or exceeds the permitted use, you will need to obtain permission directly from the copyright holder. To view a copy of this licence, visit http://creativecommons.org/licenses/by/4.0/.

\section{References}

Akers RL (2009) Social Learning and Social Structure: A General Theory of Crime and Deviance. Transaction Publishers, New Brunswick, NJ

Antonaccio O, Tittle CR (2008) Morality, self-control, and crime. Criminology 46(2):479-510

Baumeister RF, Exline JJ (1999) Virtue, personality, and social relations: Self-control as the moral muscle. J Personal Soc Psychol 67(6):1165-1194

Bruinsma GJN, Pauwels LJR, Weerman FM, Bernasco W (2015) Situational Action Theory: Cross-sectional and cross-lagged tests of its core propositions. Can J Criminol Criminal Justice 57:363-398

Eifler S (2015) Situation und Kontrolle: Eine Anwendung der Situational Action Theory auf Gelegenheiten zur Fundunterschlagung. Monatsschrift für Kriminol und Strafrechtsreform 98(3):227-257

Enzmann D (2015) Anzeigequoten als Indikator des Nichtwissens: Mess- und Konstruktionsprobleme. In: Guzy N, Birkel C, Mischkowitz R (eds) Viktimisierungsbefragungen in Deutschland, Band 2: Methodik und Methodologie. Bundeskriminalamt, Wiesbaden, pp 121-150

Enzmann D, Kivivuori J, Marshall IH, Steketee M, Hough M, Killias M (2018) A Global Perspective on Young People as Offenders and Victims: First Results from the ISRD3 Study (SpringerBriefs in Criminology). Springer, Cham, $\mathrm{CH}$

Gelman A (2008) Scaling regression inputs by dividing by two standard deviations. Stat Med 27:2865-2873

Grasmick HG, Tittle CR, Bursik RJ, Arneklev BJ (1993) Testing the core empirical implications of Gottfredson and Hirschi's general theory of crime. J Res Crime Delinquency 30:5-29

Higgins GE (2005) Can low self-control help with the understanding of the software piracy problem? Deviant Behav 26:1-24

Higgins GE, Makin DA (2004) Does social learning theory condition the effects of low self-control on college students' software piracy? J Economic Crime Manage 2(2):1-22

Hilbe JM (2011) Negative Binomial Regression, 2nd edn. Cambridge University Press, Cambridge, UK

Hirtenlehner H (2015) "Gelegenheit macht Diebe!“" oder "Wer raucht, der stiehlt!" Der Beitrag der Situational Action Theory zur Erklärung der Ladendiebstahlskriminalität junger Menschen. Monatsschrift für Kriminol und Strafrechtsreform 98(3):257-279

Hirtenlehner H, Kunz F (2016) The interaction between self-control and morality in crime causation among older adults. Eur J Criminol 13:393-409

Hirtenlehner H, Leitgöb H (2021) Differential self-control effects: Moral filtering and the subsidiary relevance of self-control. Int Criminol. https://doi.org/10.1007/s43576-021-00012-3 
Hirtenlehner H, Reinecke J (2018) Introduction to the Special Issue with some reflections on the role of selfcontrol in Situational Action Theory. Eur J Criminol 15:3-9

Hox JJ (2010) Multilevel Analysis: Techniques and Applications, 2nd edn. Routledge, New York

Ivert A-K, Andersson F, Svensson R, Pauwels LJR, Levander T, M (2018) An examination of the interaction between morality and self-control in offending: A study of differences between girls and boys. Criminal Behav Mental Health 28(3):282-294

Kammigan I (2017) "It's all about interactions": Eine empirische Untersuchung von Schulgewalt, Normorientierungen und Kontrollen aus Sicht der Situational Action Theory (edition hh 42). Wissenschaftlicher Verlag Berlin, Berlin

Kammigan I, Enzmann D, Pauwels LJR (2019) Over- and underreporting of drug use: A cross-national inquiry of social desirability through the lens of situational action theory. Eur J Criminal Policy Res 25:273-296

Karlson KB, Holm A, Breen R (2012) Comparing regression coefficients between same-sample nested models using logit and probit: A new method. Sociol Methodol 42:286-313

Kroneberg C, Schulz S (2018) Revisiting the role of self-control in Situational Action Theory. Eur J Criminol 15:56-76

Kroneberg C, Heintze I, Mehlkop G (2010) The interplay of moral norms and instrumental incentives in crime causation. Criminology 48(1):259-294

Kuha J, Mills C (2020) On group comparisons with logistic regression models. Sociol Methods Res 49(2):498-525

Li SD (2004) The impacts of self-control and social bonds on juvenile delinquency in a national sample of midadolescents. Deviant Behav 25(4):351-373

Mood C (2010) Logistic regression: Why we cannot do what we think we can do, and what we can do about it. Eur Sociol Rev 26:67-82

Pauwels L (2012) How similar is the interaction between low self-control and deviant moral beliefs in the explanation of adolescent offending? An inquiry in sub groups by gender and immigrant background. In: Fruili AS, Veneto LD (eds) Psychology of Morality. Nova Science Publishers, New York, pp 141-153

Pauwels L (2015) Über die Haltbarkeit der in der Situational Action Theory beschriebenen Interaktionseffekte in verschiedenen Bevölkerungsgruppen. Monatsschrift für Kriminol und Strafrechtsreform 97(3):280-296

Pauwels LJR (2018) The conditional effects of self-control in situational action theory. A preliminary test in a randomized scenario study. Deviant Behav 39:1450-1466

Schepers D, Reinecke J (2018) Conditional relevance of controls: A simultaneous test of the influences of self-control and deterrence on criminal behaviour in the context of Situational Action Theory. Eur J Criminol 15:77-92

Schoepfer A, Piquero AR (2006) Self-control, moral beliefs, and criminal activity. Deviant Behav 27:51-71

Seddig D (2014) Peer group association, the acceptance of norms and violent behaviour: A longitudinal analysis of reciprocal effects. Eur J Criminol 11:319-339

Steketee M (2012) The lifestyles of youth and their peers. In: Junger-Tas J, Marshall IH, Enzmann D, Killias M, Steketee M, Gruszczynska B (eds) The Many Faces of Youth Crime: Contrasting Theoretical Perspectives on Juvenile Delinquency Across Countries and Cultures. Springer, New York, pp 237-255

Stocker H (2014) Einführung in die angewandte Ökonometrie: Kapitel 7: Marginale Effekte \& nichtlineare Funktionsformen. Universität Innsbruck. https://docplayer.org/39336363-Marginale-effekte-nichtlineare-funktionsformen.html. Accessed 27 May, 2021

Svensson R, Pauwels L, Weerman FM (2010) Does the effect of self-control on adolescent offending vary by level of morality? A test in three countries. Criminal Justice Behav 37:732-743

Thomas K, McGloin JM (2013) A dual-systems approach for understanding differential susceptibility to processes of peer influence. Criminology 51:435-474

Tittle CR, Ward DA, Grasmick HG (2004) Capacity for self-control and individuals' interest in exercising self-control. J Quant Criminol 20(2):143-172

Wikström P-OH (2004) Crime as alternative: Towards a cross-level Situational Action Theory of crime causation. In: McCord J (ed) Beyond Empiricism: Institutions and Intentions in the Study of Crime. Advances in criminological theory, vol 13. Transaction Publishers, New Brunswick, NJ, London, pp 1-37

Wikström P-OH (2006) Individuals, settings, and acts of crime: Situational mechanisms and the explanation of crime. In: Wikström P-OH, Sampson RJ (eds) The Explanation of Crime: Context, Mechanisms, and Development. Cambridge University Press, Cambridge, UK, pp 61-107

Wikström P-OH (2010) Explaining crime as moral actions. In: Hitlin S, Vaisey S (eds) Handbook of the Sociology of Morality. Springer, New York, pp 211-239

Wikström P-OH, Svensson R (2010) When does self-control matter? The interaction between morality and self-control in crime causation. Eur J Criminol 7:395-410 
Wikström P-OH, Treiber K (2007) The role of self-control in crime causation: Beyond Gottfredson and Hirschi's general theory of crime. Eur J Criminol 4:237-264

Wikström P-OH, Treiber K (2009) Violence as situational action. Int J Conflict Violence 3(1):75-96

Wikström P-OH, Oberwittler D, Treiber K, Hardie B (2012) Breaking rules: The social and situational dynamics of young people's urban crime. Oxford University Press, Oxford

Wooldridge JM (2013) Introductory Econometrics: A Modern Approach, 5th edn. South-Western, Cengage Learning, Mason, $\mathrm{OH}$

Publisher's Note Springer Nature remains neutral with regard to jurisdictional claims in published maps and institutional affiliations. 